$\underline{\text { Original Article }}$

\title{
PRESCRIPTION ANALYSIS, DRUG INTERACTION CHECKING AND IMPACT OF PATIENT COUNSELING BY A CLINICAL PHARMACIST IN TYPE II DIABETES MELLITUS PATIENTS IN A TERTIARY CARE HOSPITAL-A PROSPECTIVE STUDY
}

\author{
D. KRISHNARAJAN, B. SHIVA RANJINI, ARYA M. S., SMINU SUNNY
}

JKKMMRF'S Annai JKK Sampoorani Ammal College of Pharmacy, Ethirmedu, B. Komarapalayam 638183, Namakkal Dt, TamilNadu Email: jmsaa25@gmail.com

Received: 30 Oct 2019, Revised and Accepted: 18 May 2020

\section{ABSTRACT}

Objective: To evaluate the clinical pharmacist role in the prescription analysis, drug interaction and the impact of patient counseling in type 2 diabetes mellitus patients.

Methods: A prospective study was conducted in 203 type II Diabetes Mellitus patients for a period of 6 mo in the Diabetology department Prescriptions were analyzed and self-care assessment for good health practices were collected using a questionnaire and the adherence scores were calculated. Patient counseling was provided to the patient and a follow up was done using the same self care assessment questionnaire.

Results: Out of 203 patients, 86 multiple therapy, 68 dual therapy and 49 monotherapy were observed. Glimepiride+Metformin (54), a combination of short acting and intermediate-acting insulin (41) was the most commonly prescribed drugs. Out of 1102 drugs, 488 were anti diabetic drugs, 35 were antibiotics, 579 were other drug classes prescribed. The drug interactions were reported. The adherence score shows a highly significant impact after counseling.

Conclusion: The results of the current study helps to understand the changes in prescription pattern, drug interactions and the impact of patient counseling by a clinical pharmacist.

Keywords: Diabetes Mellitus, Prescription analysis, Drug Interaction, Patient counseling

(C) 2020 The Authors. Published by Innovare Academic Sciences Pvt Ltd. This is an open access article under the CC BY license (http://creativecommons.org/licenses/by/4.0/] DOI: http://dx.doi.org/10.22159/ijpps.2020v12i7.36213. Journal homepage: https://innovareacademics.in/journals/index.php/ijpps

\section{INTRODUCTION}

Diabetes mellitus (DM) is a chronic metabolic disorder characterized by the presence of hyperglycemia accompanied by impairment in the metabolism of carbohydrates, lipids, and proteins. DM can vary greatly, but always include defects in either secretion of insulin or response or both at some point in the course of the disease [1]. The prevalence of diabetes mellitus (DM) has risen dramatically in adults worldwide from $6.6 \%$ in 2010 and estimated to be $7.8 \%$ by 2030 , with India contributing to the major part Diabetes mellitus, the chronic disease requires comprehensive management including pharmacological and nonpharmacological measures for achieving optimal glycemic control and better therapeutic outcomes to enhance the quality of life [2]

Patient's poor knowledge on the disease and its management and medication non-adherence lead to inadequate management of diabetes. Patient education is the most effective way to improvise patient responsibility towards disease management and minimize diabetes complications and improve the outcomes. This corroborates the importance of awareness among diabetics in DM management. Studies have confirmed about the positive influence of pharmacist mediated education on knowledge, attitude, and practices about disease and therapy, which has shown a positive impact on health-related quality of life [3].

Medication adherence is defined as the extent to which a patient's medication-taking behaviour coincides with the intention of the health advice he or she has been given. It is the most important factor that determines therapeutic outcomes, especially in patients suffering from a chronic illness like diabetes mellitus. The pharmacist can contribute and play a major role in the assessment of patients understanding about the illness and the therapy and communicate the benefits of treatment and assess the patient's readiness for the care plan and discuss any barriers to adherence that patients may have [3].

However, the effectiveness of the treatment for diabetes relies upon the degree of medication adherence towards the endorsed treatment. As per the World Health Organization (WHO), guideline adherence is up to, which degree an individual behaviour; following a diet, receiving medication, and executing lifestyle changes corresponds with recommendations from the health care provider. Non-adherence to medication is most basic among patients with diabetes. Inadequate adherence compromises safety and prompts ineffective treatment, which ascends in mortality and morbidity rate. Medication adherence is essential for successful treatment in patients with DM results in a better outcome, for example, hemoglobin $\mathrm{A} 1 \mathrm{C}$ values reduce the risk of hospitalization and mortality as well as the health care costs will be diminished.

The prescription analysis and the patient counseling by a clinical pharmacist will provide valuable information regarding the prescription trends and provides the physician about the drug therapy, which helps to improve the quality of care and decreases the healthcare costs. The objective of the study is to evaluate the clinical pharmacist role in the prescription analysis, drug interaction and the impact of patient counseling in type 2 diabetes mellitus patients.

\section{MATERIALS AND METHODS}

\section{Study design and ethical considerations}

This was a prospective study conducted in the outpatient department of a tertiary care hospital after obtaining the approval of the institutional ethics committee (REF NO: EC/PHARM D/2019-03).

\section{- Study site}

The study was conducted in the Endocrinology and Diabetology Department.

\section{- Study population}

203 patients with type 2 Diabetes Mellitus who receive Diabetic medication on regular basis in addition to patient counseling. Based on Raosoft sample size calculator and previously conducted studies. 


\section{- Study period}

A prospective study was carried out over a period of six months from February 2019 to July 2019.

\section{- Study criteria}

Inclusion criteria Patients with type 2 Diabetes mellitus of age group between 35 to 85 y, Patients of both genders and Patients with comorbities. Exclusion criteria: patients with Gestational Diabetes Mellitus, patients with Type 1 Diabetes mellitus, Inpatients and Patients who are not accepting the consent.

\section{$>$ Data analysis and interpretation}

The subjects were described in respect of their demographic and clinical profiles according to the type of variables such as continuous and categorical variables. In respect of continuous variables, the averages were used. The interpretations were done by student paired " $\mathrm{t}$ " test within the subjects. The categorical variables were interpreted by Wilcoxon rank sign test. The above statistical procedures were performed with the help of the statistical package namely IBM SPSS Statistics-20. The values less than or equal to $0.05(\mathrm{P} \leq 0.05)$ were fixed as statistically significant.

\section{RESULTS}

Out of 203 patients, majority of the study population were male 121 $(59.6 \%)$ and female were $82(40.4 \%)$ (table 1$)$. The majority of study subjects were from the age group of $55-64$ y which is $36.5 \%$ of the population, followed by 65-74 y (23.6\%), 45-54 y(22.2\%), 35-44 $\mathrm{y}(16.7 \%)$ and the least was in the age group of $75-84 \mathrm{y}(1 \%)$. The mean age of total subjects was $55.8 \pm 10.4 \mathrm{y}$ with range of $35-84 \mathrm{y}$ (table 2). The subjects having the family history were $69(34.0 \%)$ and not having the family history were 134 (66\%) among the total study population (table 3 ).

Table 1: Gender wise distribution of study subjects $(\mathrm{N}=203)$

\begin{tabular}{llll}
\hline S. No. & Gender & Frequency & Percentage (\%) \\
\hline 1 & Male & 121 & 59.6 \\
2 & Female & 82 & 40.4 \\
Total & & 203 & 100.0 \\
\hline
\end{tabular}

Table 2: Description of study subjects according to their Age

\begin{tabular}{lllll}
\hline S. No. & Age group (years) & Frequency & Percentage (\%) & mean \pm SD \\
\hline 1 & $35-44$ & 34 & 16.7 & $38.5 \pm 2.8$ \\
2 & $45-54$ & 45 & 22.2 & $50.0 \pm 2.6$ \\
3 & $55-64$ & 74 & 36.5 & $58.8 \pm 3.0$ \\
4 & $65-74$ & 48 & 23.6 & $67.9 \pm 2.6$ \\
5 & $>75$ & 2 & 1.0 & $75.5 \pm 0.7$ \\
Total & & 203 & 100.0 & $55.8 \pm 10.4$ \\
\hline
\end{tabular}

Table 3: Family history wise distribution of study subjects $(\mathrm{N}=203)$

\begin{tabular}{llll}
\hline S. No. & Family history & Frequency & Percentage (\%) \\
\hline 1 & Patients with Family history & 69 & 34.0 \\
2 & Patients with No family history & 134 & 66.0 \\
Total & & 203 & 100.0 \\
\hline
\end{tabular}

The social history shows that patients having the habit of alcoholism was $16(7.9 \%)$ and smoking was $12(5.9 \%)$. The remaining $175(86.2 \%)$ of subjects were not having any social histories (fig. 1). 72(35.5\%) patients reported that they have no co-morbidities. The most commonly reported co-morbidity was Hypertension 75(36.9\%), followed by dyslipidemia
$38(18.7 \%)$, coronary artery disease $15(7.4 \%)$ and cerebrovascular accident 3 (1.5\%) (fig. 2). Neuropathy 46 patients $(22.7 \%)$ was the highly observed complication followed by nephropathy 9 patients $(4.4 \%)$ and retinopathy 7 patients $(3.4 \%) .141$ patients $(69.5 \%)$ did not have any complications (table 4 ).

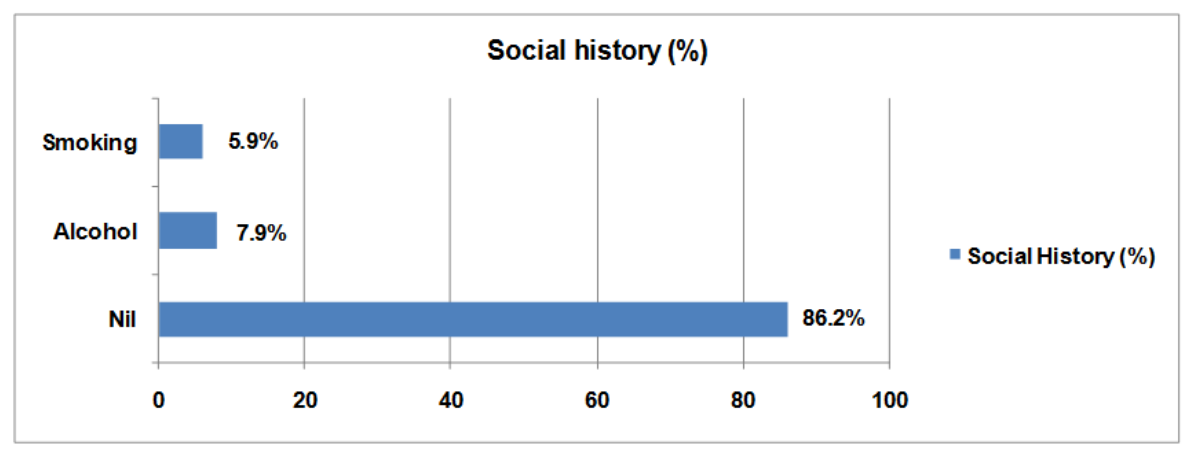

Fig. 1: Percentage distribution of social histories

Table 4: Complications of study subjects

\begin{tabular}{llll}
\hline S. No. & Complications & Frequency & \% \\
\hline 1 & Neuropathy & 46 & 22.7 \\
2 & Nephropathy & 9 & 4.4 \\
3 & Retinopathy & 7 & 3.4 \\
4 & Nil & 141 & 69.5 \\
Total & & 203 & 100.0 \\
\hline
\end{tabular}




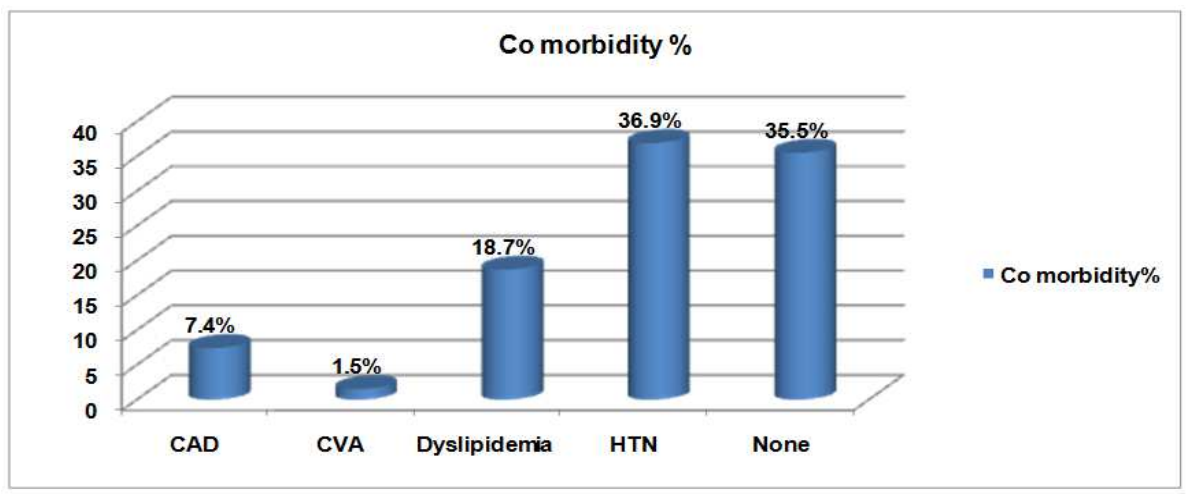

Fig. 2: Percentage distribution of co morbidity

Multiple therapy was the highly followed therapy 86 (42.36\%), dual therapy was administered to $68(33.50 \%)$ and mono therapy was administered to $49(24.14 \%)$ of subjects (fig. 3). The maximum of subjects $85(41.3 \%)$ have the duration as $1-5 \mathrm{y}$ and the least duration was $15-20$ y as 19 (9.4\%). The total mean duration was $6.6 \pm 5.1 \mathrm{y}$ (table 5). Glimepiride+Metformin combination 54 was the highly prescribed oral hypoglycemic agent followed by Glimepiride 53 (table 6 and 7).

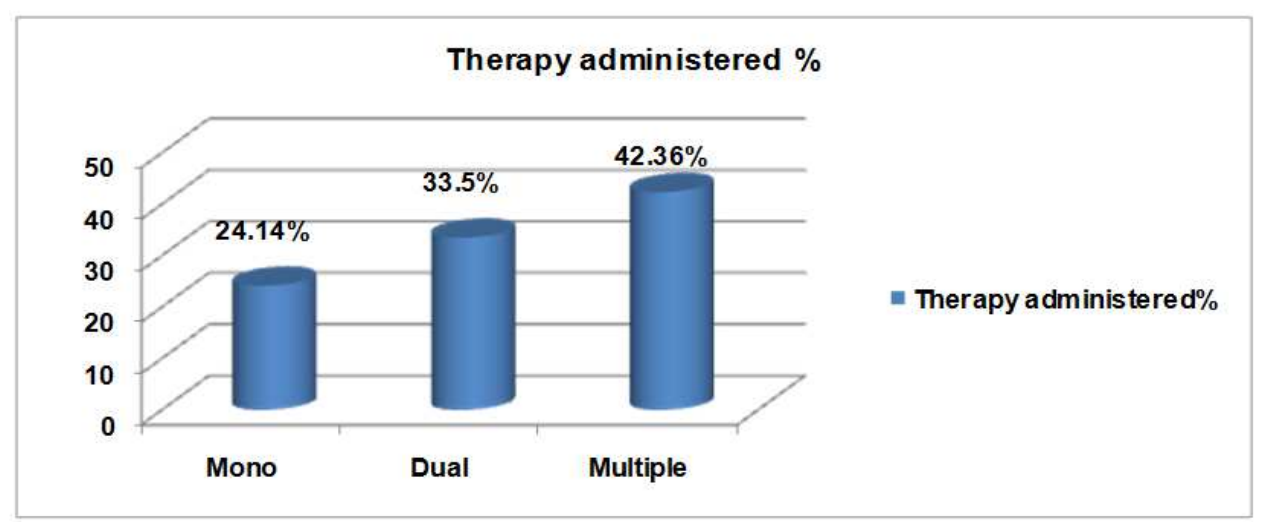

Fig. 3: Percentage of therapy administered

Table 5: Duration of diabetic mellitus

\begin{tabular}{lllll}
\hline S. No. & Duration of DM (years) & Frequency & Percentage (\%) & mean \pm SD \\
\hline 1 & Below 5 & 84 & 41.3 & $2.3 \pm \mathbf{1 . 0}$ \\
2 & $5-10$ & 55 & 27.1 & $11.0 \pm \mathbf{1 . 0}$ \\
3 & $10-15$ & 45 & 22.2 & $18.0 \pm 2.2$ \\
4 & 15 and above & 19 & 9.4 & $6.6 \pm \mathbf{5 . 1}$ \\
Total & & 203 & 100.0 & \\
\hline
\end{tabular}

Table 6: Current drugs administered (single drugs)

\begin{tabular}{lll}
\hline S. No. & Drugs & Frequency \\
\hline 1 & Glimepiride & 53 \\
2 & Metformin & 31 \\
3 & Teneligliptin & 30 \\
4 & Pioglitazone & 29 \\
5 & Vildagliptin & 24 \\
6 & Voglibose & 23 \\
7 & Gliclazide & 18 \\
8 & Empagliflozin & 7 \\
9 & Sitagliptin & 5 \\
10 & Linagliptin & 5 \\
11 & Dapagliflozin & 3 \\
12 & Glibenclamide & \\
13 & Canaglifloxin & \\
15 & Gemigliptin & \\
\\
\hline
\end{tabular}


Table 7: Combinations

\begin{tabular}{lll}
\hline S. No. & Drugs & Frequency \\
\hline 1 & Glimepiride+Metformin & 54 \\
2 & Gliclazide+Metformin & 16 \\
3 & Metformin+Teneligliptin & 13 \\
4 & Glimepiride+Metformin+Voglibose & 11 \\
5 & Glibenclamide+Metformin & 10 \\
6 & Metformin+Vildagliptin & 9 \\
7 & Metformin+Sitagliptin & 9 \\
8 & Glipizide+Metformin & 5 \\
9 & Glimepiride+Metformin+Pioglitazone & 4 \\
10 & Metformin+Voglibose & 3 \\
11 & Metformin+Saxagliptin & 3 \\
12 & Empagliflozin+Linagliptin & 2 \\
13 & Glimepiride+Pioglitazone & 2 \\
\hline
\end{tabular}

Among the types of insulin used, the combination of short acting and intermediate acting insulin (41) was the maximum prescribed and the combination of long acting and rapid acting insulin (1) was the least prescribed (table 8). The prescription trend were analyzed in 203 patients. A total of 1102 drugs were prescribed to the type 2 diabetes mellitus patients and the average number of drugs per prescription was 6 in number. Total number of anti-diabetics out of the total number of drugs prescribed was 488 (table 9). The type of severity of drug interaction in the study population shows that $32(84.21 \%)$ moderate interactions were theoretically observed in the prescription, $5(13.16 \%)$ of minor interactions and $1(2.63 \%)$ of major interaction was also noticed. The major drug interactions was found with Tab. Glimepiride and Tab. Fluconazole. The moderate drug interaction was found between Tab. Pioglitazone and Insulin Glargine (table 10).

Table 8: Types of insulin

\begin{tabular}{lll}
\hline S. No. & Types of insulin & Frequency \\
\hline 1 & Rapid acting insulin & 22 \\
2 & Intermediate acting insulin & 9 \\
3 & Long acting insulin & 31 \\
4 & Combination of short acting and intermediate acting insulin & 41 \\
5 & Combination of rapid acting and intermediate acting insulin & 7 \\
6 & Combination of long acting and rapid acting insulin & 1 \\
\hline
\end{tabular}

Table 9: Prescription details in diabetes mellitus patients

\begin{tabular}{ll}
\hline Details of prescription & Number \\
\hline Total number of prescriptions analyzed & 203 \\
Total number of drugs prescribed & 1102 \\
Average number of drugs per prescription & 6 \\
Number of injections out of total number of drugs prescribed & 111 \\
Total number of anti diabetics out of total number of drugs prescribed & 488 \\
Number of encounters with an antibiotic prescribed & 35 \\
Total Number of Other Drugs & 579 \\
\hline
\end{tabular}

Table 10: Description based on drug interaction

\begin{tabular}{llll}
\hline S. No. & Severity & Frequency & Percentage (\%) \\
\hline 1 & Major & 1 & 2.63 \\
2 & Moderate & 32 & 84.21 \\
3 & Minor & 5 & 13.16 \\
Total & & 38 & 100 \\
\hline
\end{tabular}

The effectiveness of counseling was analyzed from pre to post tests in respect of physical activity, BMI and self scale assessment questionnaires. Before the counselling the subjects on physical activity was $72(35.47 \%)$, whereas after counseling there seems to be a significant increase in the number of patients on physical activity as 127 (62.56\%) (table 11). The total number of patients with normal BMI has increased after the counseling and the number of patients with overweight has decreased after counseling (table 12).

Table 11: Distribution based on physical activity

\begin{tabular}{|c|c|c|c|c|c|c|c|c|}
\hline \multirow[t]{2}{*}{ S. No. } & \multirow{2}{*}{$\begin{array}{l}\text { Physical } \\
\text { activity }\end{array}$} & \multicolumn{2}{|l|}{ Before } & \multicolumn{2}{|l|}{ After } & \multirow[t]{2}{*}{ Df } & \multirow[t]{2}{*}{$\mathbf{X}^{2}$} & \multirow{2}{*}{$\begin{array}{l}\text { Chi square test } \\
\text { Test statistics }\end{array}$} \\
\hline & & Frequency & $\%$ & Frequency & $\%$ & & & \\
\hline 1 & Yes & 72 & 35.47 & 127 & 62.56 & 1 & 63.621 & $\mathrm{P}<0.001$ \\
\hline 2 & No & 131 & 64.53 & 76 & 37.44 & & & \\
\hline Total & & 203 & 100 & 203 & 100 & & & \\
\hline
\end{tabular}


Table 12: Distribution of subjects according to their pre and post BMI

\begin{tabular}{|c|c|c|c|c|c|c|c|}
\hline \multirow[t]{2}{*}{ S. No. } & \multirow[t]{2}{*}{ BMI } & \multicolumn{3}{|l|}{ Before } & \multicolumn{3}{|l|}{ After } \\
\hline & & Frequency & $\%$ & mean \pm SD & Frequency & $\%$ & mean \pm SD \\
\hline 1 & $<18.5$ & 3 & 1.5 & $16.7 \pm 0.8$ & 3 & 1.5 & $16.4 \pm 1.0$ \\
\hline 2 & $18.5-25$ & 78 & 38.4 & $22.7 \pm 1.6$ & 83 & 40.9 & $22.7 \pm 1.6$ \\
\hline 3 & $25-30$ & 87 & 42.9 & $27.1 \pm 1.2$ & 82 & 40.4 & $27.1 \pm 1.2$ \\
\hline 4 & $30-35$ & 24 & 11.8 & $31.4 \pm 1.2$ & 26 & 12.8 & $31.5 \pm 1.2$ \\
\hline 5 & $35+$ & 11 & 5.4 & $38.9 \pm 3.6$ & 9 & 4.4 & $38.8 \pm 3.4$ \\
\hline Total & & 203 & 100.0 & $26.4 \pm 4.6$ & 203 & 100.0 & $26.2 \pm 4.4$ \\
\hline
\end{tabular}

All the patients were undergone through the self scale assessment questionnaires on good health practices prior to the counseling and during the first follow-up. An improvement was observed in respect to medication adherence after the counseling [Questions 1, 2 and 3]. A positive result was observed in respect to dietary recommendations after the counseling [Questions 4 and 5]. A positive result was observed in respect to physical activity after the counseling [Questions 6]. A greater improvement was observed in the monitoring parameters after the counseling [Questions $7,8,9,10,11$ and 12] (table 13). The Wilcoxon rank sign test revealed that the adherence improvements was statistically very highly significant $(\mathrm{P}<0.001)$ (table 14).

Table 13: Self scale assessment questionnaire

\begin{tabular}{|c|c|c|c|c|c|}
\hline \multirow{2}{*}{$\begin{array}{l}\text { S. } \\
\text { No. }\end{array}$} & \multirow[t]{2}{*}{ Questionnaries } & \multicolumn{2}{|l|}{ Pre counseling } & \multicolumn{2}{|c|}{ Post counseling } \\
\hline & & Yes & No & Yes & No \\
\hline 1 & $\begin{array}{l}\text { Medication based: } \\
\text { Do you take your medications on time without missing the } \\
\text { doses? }\end{array}$ & $153(75.37 \%)$ & $50(24.63 \%)$ & $200(98.52 \%)$ & $3(1.48 \%)$ \\
\hline 2 & Do you adjust your medication by yourself? & $17(8.37 \%)$ & $186(91.63 \%)$ & $2(0.99 \%)$ & $201(99.01 \%)$ \\
\hline 3 & $\begin{array}{l}\text { Do you follow any other system of medicines (such as } \\
\text { Siddha/Ayurvedha/Unani)? }\end{array}$ & $1(0.49 \%)$ & $202(99.51 \%)$ & $1(0.49 \%)$ & $202(99.51 \%)$ \\
\hline 4 & $\begin{array}{l}\text { Diet based: } \\
\text { Do you sometimes skip your food? }\end{array}$ & $79(38.92 \%)$ & $124(61.10 \%)$ & $30(14.78 \%)$ & $173(85.22 \%)$ \\
\hline 5 & $\begin{array}{l}\text { Do you follow the dietary recommendations given by your } \\
\text { doctor or dietician or diabetic specialist? }\end{array}$ & $134(66.01 \%)$ & $69(33.10 \%)$ & $160(78.82 \%)$ & $43(21.18 \%)$ \\
\hline 6 & $\begin{array}{l}\text { Physical activity: } \\
\text { Do you exercise daily? }\end{array}$ & $72(35.47 \%)$ & $131(64.53 \%)$ & $127(62.56 \%)$ & $76(37.44 \%)$ \\
\hline 7 & $\begin{array}{l}\text { Monitoring parameters: } \\
\text { Are you regularly monitoring the blood glucose level with } \\
\text { care and attention? }\end{array}$ & $105(51.72 \%)$ & $98(48.28 \%)$ & $154(75.86 \%)$ & $49(24.14 \%)$ \\
\hline 8 & Do you check your eyes at least once in a year? & $131(64.53 \%)$ & $72(35.47 \%)$ & $161(79.31 \%)$ & $42(20.69 \%)$ \\
\hline 9 & Do you check your foot regularly? & $85(41.87 \%)$ & $118(58.13 \%)$ & $107(52.71 \%)$ & $96(47.29 \%)$ \\
\hline 10 & $\begin{array}{l}\text { Are you regularly monitoring other parameters (such as } \\
\text { Renal Function Test/Complete Blood Count) atleast once in } \\
\text { six months and Blood Pressure at least weekly/monthly? }\end{array}$ & $92(45.32 \%)$ & $111(54.68 \%)$ & $110(54.19 \%)$ & $93(45.81 \%)$ \\
\hline 11 & $\begin{array}{l}\text { Are you able to maintain the doctor's appointments } \\
\text { recommended for your diabetic treatment? }\end{array}$ & $99(48.77 \%)$ & $104(51.23 \%)$ & $127(62.56 \%)$ & $76(37.44 \%)$ \\
\hline 12 & $\begin{array}{l}\text { Are you able to cope up with diabetes, with the information } \\
\text { given by the Physician and Dietician? }\end{array}$ & $134(66.01 \%)$ & $69(33.99 \%)$ & $180(88.67 \%)$ & $23(11.33 \%)$ \\
\hline
\end{tabular}

Table 14: Type of adherence from before to after

\begin{tabular}{llllll}
\hline Type of adherence & \multicolumn{2}{l}{ Pre-counselling } & \multicolumn{2}{l}{ Post counselling } & Wilcoxon rank sign test \\
\cline { 2 - 6 } & Frequency & \% & Frequency & \% & Test statistics \\
\hline Adherant & 62 & 30.6 & 100 & 49.3 & \\
Moderate & 80 & 39.4 & 91 & 44.8 & $\mathrm{Z}=7.874$ \\
Non Adherant & 61 & 30.0 & 12 & 5.9 & $\mathrm{P}<0.001$ \\
Total & 203 & 100 & 203 & 100 & \\
\hline
\end{tabular}

The patients' opinion on factors that prevent optimal self-scale adherence among the non adherent type 2 diabetes mellitus patients were collected. Among them non aware of the consequences of missing the dose 61 (19.04\%) was the major factor reported followed by forgetfulness 60 (18.75\%) (table 15).

Table 15: Non adherence factors

\begin{tabular}{|c|c|c|c|}
\hline S. No. & Factors & Frequency & Percentage (\%) \\
\hline 1 & Non aware of the consequences of missing the dose & 61 & $19.04 \%$ \\
\hline 2 & Forgetfulness & 60 & $18.75 \%$ \\
\hline 3 & Self-monitoring of blood glucose was difficult & 56 & $17.5 \%$ \\
\hline 4 & Dietary restriction was difficult to maintain & 50 & $15.64 \%$ \\
\hline 5 & Lack of time for physical activity & 49 & $15.32 \%$ \\
\hline 6 & Lack of financial resources & 37 & $11.57 \%$ \\
\hline 7 & Decision to omit due to other reasons & 7 & $2.18 \%$ \\
\hline
\end{tabular}


Among the 61 non adherent patients only 52 patients had done the $\mathrm{HbA1c}$ Tests during both the visits (Pre and Post counseling) among that

- 44 Patients had a decrease in $\operatorname{HbA1C}(n=52)$
- 11 Patients had no variation in $\operatorname{HbA1C}(n=52)$

- 6 Patients has newly done HbAlc after counseling $(n=61)$ (table 16)

Table 16: HbA1c details of non-adherent patients

\begin{tabular}{|c|c|c|c|c|c|}
\hline \multirow[t]{2}{*}{ S. No. } & \multirow[t]{2}{*}{ Non-adherence } & \multicolumn{2}{|c|}{ Pre-counseling } & \multicolumn{2}{|c|}{ Post counseling } \\
\hline & & Frequency & Percentage & Frequency & Percentage \\
\hline 1 & HbA1c Done & 55 & 90.2 & 61 & 100 \\
\hline 2 & HbA1c Not Done & 6 & 9.8 & 0 & 0 \\
\hline Total & & 61 & 100 & 61 & 100 \\
\hline
\end{tabular}

The effectiveness of counseling was compared in respect of weights, BMI and adherence score from before and after counseling. The mean weights was $69.9 \pm 13.4$ and after counseling was $69.4 \pm 13.1 \mathrm{Kg}$. The difference of reduction was statistically highly significant $(\mathrm{P}<0.01)$. The mean BMI before and after were $26.4 \pm 4.6$ and $26.2 \pm 4.4$. The reductions was statistically highly significant $(\mathrm{P}<0.01)$. The before and after adherences were $7.5 \pm 2.8$ and $9.3 \pm 1$.8. The improvement of adherence was statistically very highly significant $(\mathrm{P}<0.001)$ (table 17).

Table 17: Comparison of before and after of weights, BMI and questionnaire

\begin{tabular}{|c|c|c|c|c|c|c|c|c|c|}
\hline \multirow[t]{2}{*}{ Variables } & \multicolumn{2}{|l|}{ Before } & \multicolumn{2}{|l|}{ After } & \multicolumn{2}{|c|}{ Improved } & \multirow[t]{2}{*}{ "t" } & \multirow[t]{2}{*}{ Df } & \multirow[t]{2}{*}{ Sig } \\
\hline & Mean & SD & Mean & SD & Mean & SD & & & \\
\hline Weights & 69.9 & 13.4 & 69.4 & 13.1 & 0.5 & 2.3 & 2.789 & 202 & $\mathrm{P}=0.006$ \\
\hline BMI & 26.4 & 4.6 & 26.2 & 4.4 & 0.2 & 0.9 & 3.247 & 202 & $P=0.001$ \\
\hline Adherence & 7.5 & 2.8 & 9.3 & 1.8 & 2.1 & 1.8 & 12.614 & 202 & $P<0.001$ \\
\hline
\end{tabular}

\section{DISCUSSION}

Based on the gender distribution, the study conducted by Javedh Shareef et al. [4] found that the male were in greater proportion than female. However, the same result was also observed in our study. The study conducted by Javedh Shareef et al. [4] states that the age group between 51-60 y were at greater proportions than the other age groups and also the study conducted by Arif Jemal et al. [6] concluded that the study population greater than $60 \mathrm{y}$ were in higher proportions compared to other age groups, whereas in our study the age group between 55-64years were greater in proportion.

The study reported by Arif Jemal et al. [6] concluded that patients with no family history 182 (92.9\%) were at greater proportion than patients with family history 14 (7.1\%). Henceforth, our study also concluded that patients with no family history $134(66 \%)$ was greater than patients with family history 69 (34.0\%). In accordance with the social history distribution, the study conducted by Arif Jemal et al. [6] reported that patients who are free of any social habits 111 (56.6\%) were in higher proportion. Among the patients with social habits, chat chewers $82(41.8 \%)$ were predominant. Similarly, in our study the patients who are free of any social habits were in higher proportion i.e. $175(86.2 \%)$ patients. But in case of patients with social habits, the alcoholic users were predominant i.e. $16(7.9 \%)$ of the study population. The study of Arif Jemal et al. [6] reported that forgetfulness $31(53.45 \%)$ was the predominant non adherence factor followed by other reasons $23(39.66 \%)$ such as side effects, poor patient provider relationships etc.

The study conducted by Sahoo Subhasish et al. [18] reported that hypertension 12 (25\%) was the major co-morbidity among the study population followed by ketosis $11(18.3 \%)$. Hence in our study, hypertension 75 (36.9\%) seems to be the major co-morbidity and 72 $(35.5 \%)$ patients reported that they have no co-morbidities. The study enclosed by Sahoo Subhasish et al. [19] detected that 6 moderate, 4 minor and 2 major drug interaction among 60 study population, whereas a similar range of severity was observed with different class of drugs in our study.

The study of Mohd Mahmood et al. [19] reported that Biguanides (Metformin-57.3\%) was the highly prescribed drug in the study population, whereas our study reported that the combination of Glimepiride+Metformin-(54 in number) as the highly prescribed medication followed by second generation sulfonylureas (Glimepiride-53 in number).
The study report of Manjusha S et al. [20] on prescription analysis reveals that 105 prescriptions were analyzed, 1281 drugs were prescribed and the average number of drugs per prescription was 12.2. Out of the total drugs prescribed, 171 (13.35\%) were antidiabetics, 441 (34.43\%) were injections and 59 (4.61\%) were antibiotics.

Among 203 patients the effectiveness of counseling shows an improvement in the adherence rate. The Wilcoxon rank sign test revealed that the adherence improvements was statistically very highly significant $(\mathrm{P}<0.001)$. From the result of the above study shows that the patient counseling by the clinical pharmacist place a major role in improving the patient's health status.

\section{LIMITATIONS}

The study population was lesser in number. The theoretical observation of drug interaction was unable to correlate with the clinical occurrence due to changes in the time schedule and the cost of illness was not involved in the study.

\section{CONCLUSION}

The results of the current study helps to understand the changes in prescription pattern and to identify the drug interactions among the prescribed medications. The results also suggests that the patient counseling provided by a clinical pharmacist have a greater impact in the improvement of patients knowledge about the disease, importance of medication adherence and the necessary self care practices to be followed in order to maintain a better glycemic control and prevention of further complications of the disease.

\section{ACKNOWLEDGEMENT}

We heartfully thank Dr. D. KRISHNARAJAN, M. Pharm., Ph. D., (Head and Professor, Department of Pharmacy Practice) and Dr. SHIVA RANJINI, Pharm. D., (Assistant Professor, Department of Pharmacy Practice), Annai JKK Sampoorani Ammal College of Pharmacy, Komarapalayam for providing their immense support throughout our study.

\section{FUNDING}

Nil

\section{AUTHORS CONTRIBUTIONS}

All authors have contributed equally in this piece of work. 


\section{CONFLICT OF INTERESTS}

The authors have no conflict of interest to disclose.

\section{REFERENCES}

1. Prathyusha Rani T, Prashanthi B, Ayesha Amreen Fathima, Ayesha Firdose, Sara Naser, Najma Begum, et al. Medication adherence in patients with type 2 diabetes mellitus-a crosssectional study. Asian J Pharm Clin Res 2019;12:177-80.

2. World Health Organisation. Available from: https://www.who.int/news-room/factsheets/details/diabetes. [Last accessed on 30 Oct 2018]

3. Adepu SPR, S Sam, C Omanakuttan, RKV, Y Yashaswini. Assessment of pharmacist mediated education on medication adherence behavior in type 2 diabetes mellitus patients in south indian rural population. Int J Pharm Pharm Sci 2018;10:39-43.

4. Javedh Shareef Jennifer Fernandes, Laxminarayana Samaga, Bhat ML. Evolving role of clinical pharmacist in the management of diabetes mellitus. Int J Res Med Sci 2015;7:3.

5. Ann Mary Swaroop, Christina Varghese, Josmine Jose. Impact of patient counselling on knowledge, attitude, practice and medication adherence in type 2 diabetes mellitus patients. Eur J Pharm Med Res 2016;3:231-5.

6. Arif Jemal, Jemal Abdela, Mekonnen Sisay. Adherence to oral antidiabetic medications among type 2 diabetic (T2DM) patients in chronic ambulatory wards of hiwot fana specialized university hospital, harar, eastern ethiopia: a cross sectional study. J Diabetes Metab 2017;8:1.

7. Awuni Prosper Mandela Amalting. Non adherence to diabetic medication among diabetic patients, a case study of dormaa hospital ghana. Sci J Public Health 2017;5:88-97.

8. Belayneh Kefale Gelaw, Abdela Mohammed, Gobezie Temesgen Tegegne, Amsalu Degu Defersha, Muluneh Fromsa. Non adherence and contributing factors among ambulatory patients with antidiabetic medications in adama referral hospital. J Diabetes Res 2014. p. 9. https://doi.org/10.1155/ 2014/ 617041
9. Bijoy CV, Feba B, Vikas RC, Dandapani C, Geetha K, Vijayakumar A. Knowledge assessment and patient counseling on diabetic foot care. Indian J Pharm Practice 2012;5:11-5.

10. Jitendra Singh. Economic burden of diabetes: Chapter 45 . Diabetology; 2013. p. 205-8.

11. Cia Sin Lee, Jane Hwee Mian Tan, Usha Sankari, Yi Ling Eileen Koh. Assessing oral medication adherence among patients with type 2 diabetes mellitus treated with polytherapy in a developed Asian community: a cross sectional study. Br Med J Open 2017. http://dx.doi.org/10.1136/bmjopen-2017-016317

12. Comprehensive Pharmacy Review for NAPLEX. Eighth Edition. By Leon Shargel, Alan H Mutnick, Paul F. Souney and Larry N. Swanson; 2013. p. 1248.

13. Current Medical Diagnosis and Treatment. fifty eighth edition. Maxine A. Papadakis and Stephen J. McPHEE; 2019. p. 1220-68.

14. Dharini Krishnan. The impact of diet counselling on type 2 diabetes mellitus: An Indian case study; 2015.

15. Sherry Garg, Sophia Garg, MA Jamadar, Gashaw Jember, Yayehirad Alemu Melsew, Balamurugan Janakiraman. Prevalence of complications in diabetes mellitus type peripheral sensory neuropathy and associated factors among adult diabetes mellitus patients in Bahr Dar. Ethiopia 2017;2:32754-57.

16. ICMR guidelines for management of type 2 Diabetes; 2018.

17. Andreas Schmitt, Annika Gahr, Norbert Hermanns. The diabetes self management questionnaire (DSMQ): development and evaluation of an instrument to assess diabetes self-care activities associated with glycaemic control Health and Quality of Life Outcomes; 2013. p. 138.

18. Sahoo Subhasish, Dash Kiran Kaushik, Sahoo Sabita, Sahu Debasish. Prescription analysis in diabetes mellitus; 2010.

19. Mohd Mahmood, Charitha Reddy R, Soumya Lahari JR, Fatima $S$, Shinde P. Prescription pattern analysis of antidiabetic drugs in diabetes mellitus associated comorbidities. Clin Invest (Lond.) 2017;8:5-12.

20. Manjusha S, Amit M, Ronak S. A study on prescribing pattern and potential drug-drug interactions in type 2 diabetes mellitus inpatients. Indian J Pharm Practice 2014;7:7-12. 